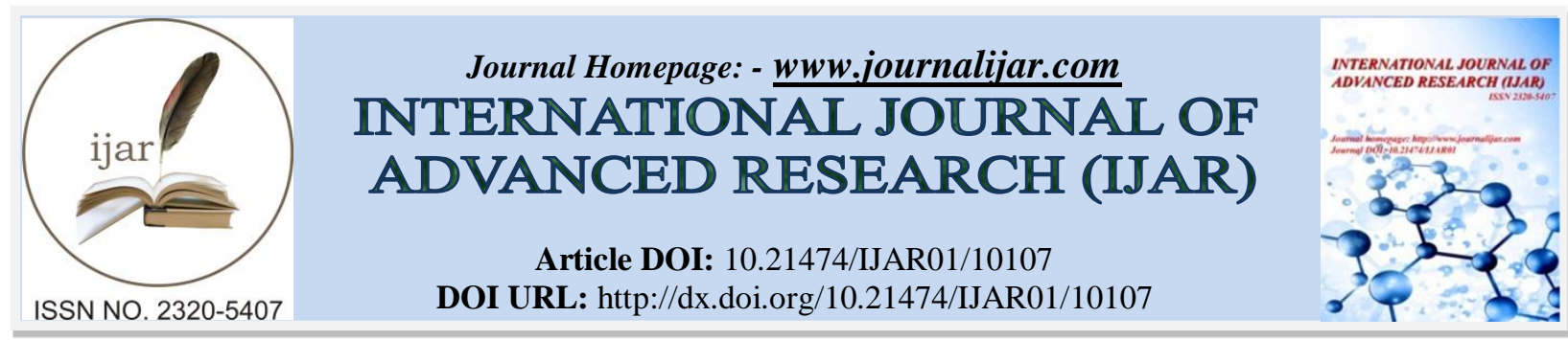

RESEARCH ARTICLE

\title{
ASSESSMENT OF BATHWEAR PATTERN OF WOMEN AND ITS ASSOCIATED PROBLEMS AT COMMUNAL PLACES.
}

Shanu Parashar and Dr. Meenu Srivastava.

Dept. of Textiles \&Apparel Designing College of Community and Applied Sciences, MPUAT, Udaipur.

\section{Manuscript Info}

Manuscript History

Received: 14 September 2019

Final Accepted: 16 October 2019

Published: November 2019

Key words:- Bath wear, Modesty, Pattern, problems.

\begin{abstract}
Rajasthan is not only known for its splendid forts and palaces but also attracts thousands of devotees and pilgrims. The holy lake of Pushkar is surrounded by ghats or embankments where the various religious ceremonies are frequently performed by the women pilgrims visiting Pushkar round the year. The present study was conducted by the researcher to identify the existing bath wear pattern and problems faced by women pilgrims while bathing and changing bath wear outfits at communal places. For this, a sample of 60 women respondents was purposively selected from the Pushkar town, clusters around the Pushkar lake of Ajmer district of the Rajasthan. The data was collected through developed structured interview schedule.
\end{abstract}

Copy Right, IJAR, 2019,. All rights reserved.

\section{Introduction:-}

Human beings wear clothing to satisfy their social need for modesty. Modesty is the covering of a person's body according to the code of decency of that person's society. Standards of modesty differ among various cultures and situations, and they change over time. By wearing appropriate or inappropriate clothing, people show their acceptance or rejection of their social environment. ${ }^{1}$ In the Hindu mythology, water is the source of life and creation, therefore rivers and riverbanks are considered to be holy. Due to the importance of the mythological meaning, the ghats are often visited by pilgrims who want to get sanctified by bathing in the water of the holy river or drink it. An important part of ritual purification in Hinduism is the bathing of the entire body, particularly in rivers considered holy such as the Ganges; it is considered auspicious to perform this form of purification before any festival, and it is also practiced after the death of someone, in order to maintain purity ${ }^{2}$

Bathwear is clothing designed to be worn by people engaging in a water-based activity or while bathing. Different types may be worn by men, women, and children. Bathwear is described by a number of names, some of which are used only in particular locations, including swimsuit, bathing suit, swimming costume, bathing costume, swimming togs, bathers, cossie (short for "costume") etc. ${ }^{3}$ Women must be decently dressed, especially when they bath in open area so that they cannot looks scandalous. Clothes should not tight, scanty, transparent, skin, showing etc. Women by dressing with modesty will gain the respect of men, becoming dignified instead of being degraded and considered a mere object of lust. Instead of dressing in a manner which is disrespectful, they should dress in accord with a higher standard. They should dress with this higher standard to receive the respect they deserve. ${ }^{4}$

Rajasthan is the largest state of India with vibrant land bestowed with a rich culture and heritage that spreads all around. The religious places in Rajasthan are not only places of worship but also monuments of great artistic beauty.

Corresponding Author:-Shanu Parashar.

Address:-Dept. of Textiles \&Apparel Designing College of Community and Applied Sciences, MPUAT, Udaipur. 
Religious Places in Rajasthan evoke a pure feeling of harmony and dignity. ${ }^{5}$ The numerous religious places of Rajasthan had beliefs of people which provide a perfect example of devotion and communal harmony. Rajasthan is not only known for its splendid forts and palaces but also attracts thousands of devotees, pilgrims and lovers at holy rivers and ghats or embankments.

Pushkar is one of the oldest towns in Rajasthan, India. Located to the northwest of Ajmer, the tranquil town of Pushkar is a favoured destination for thousands of tourists and devotees flocking to Rajasthan. Pushkar is often called 'tirtha-raj', which literally means the king of pilgrim sites. Pushkar is also famous for the Pushkar Lake, which has 52 ghats, which are stone steps to descend to the edge of the lake. Devotees flock to these ghats for a holy dip. The sacred water of this lake is believed to wash away the sins. The lake's water is believed to have curative and medicinal properties. More than 500 temples are present around the lake ${ }^{6}$ Clothing and modesty are becoming ever more serious, and important as we move into these perilous immoral times. ${ }^{7}$ Modest clothing typically includes clothing that not only covers the private parts of the body but that is also loose fitting and does not cling to the contours of the body. ${ }^{8}$ In India, as in other parts of the non-western world, coverage is simply essential for comfort. In fact, it's not rare to see women enjoying water park rides fully-dressed, floating among the crowd in a public swimming pool wearing saris or salwar kameezes. ${ }^{9}$

The present paper focuses on Assessment of Bathwear Pattern of Women pilgrims and its Associated Problems at communal Places.

\section{Methodology:-}

The study was conducted in the central area of Rajasthan state in saintly Pushkar town of Ajmer district, clusters around the Pushkar Lake. Here, the Brahma temple is a major attraction and around 52 Ghats cuddle the holy lake. The Ghats are sacred bathing places used to do religious rituals \& ceremonies and pilgrims bathe in the sacred waters. Thus, based on the objectives of the study, Pushkar, primarily a pilgrimage spot was selected to get firsthand information from the women pilgrims for survey work. Total 60 respondents were purposively selected. A pre structured interview schedule was formulated by the researcher in order to explore information about clothing needs of women while bathing in public places and problem faced by them during dressing or changing outfits in public places. The tool was comprised of the close ended questions based on the sample group. The developed schedule was pre-tested on ten non sample subjects. The collected data was analyzed for statistical treatment in the light of objective of study.

\section{Results and discussions: -}

The holy lake of Pushkar is surrounded by ghats or embankments where the various religious ceremonies are frequently conducted by the women pilgrims visiting Pushkar round the year. The researcher purposively selected 60 respondents from the Pushkar town, clusters around the Pushkar lake of Ajmer district of the Rajasthan. A survey was carried out to identify the existing bath wear pattern and problems faced by women while wearing and changing bath wear outfits. The data was collected through developed structured interview schedule. The investigator personally interviewed the respondents to gather the required information.

The data pertaining to socio personal characteristic such as age, education, religion, working status, family occupation, family income and family type have been presented in Table-1.

Table 1:-Socio-personal traits of the respondents

\begin{tabular}{|l|c|c|}
\multicolumn{2}{|c|}{$\mathrm{n}=60$} \\
\hline Socio-personal traits & Number of respondents & Percentage \\
\hline Age (in years) & 6 & 10.00 \\
\hline 20 to 30 & 16 & 26.66 \\
\hline 30 to 40 & 38 & 63.33 \\
\hline 40 to 50 & \multicolumn{2}{|c|}{} \\
\hline Working status & 21 & 35 \\
\hline Working & 39 & 65 \\
\hline Non-Working & 6 & 10 \\
\hline Education & \multicolumn{2}{|c|}{} \\
\hline Primary & \multicolumn{2}{|c|}{} \\
\hline
\end{tabular}




\begin{tabular}{|l|c|c|}
\hline Secondary & 12 & 20 \\
\hline Hr. Secondary & 18 & 30 \\
\hline Graduation & 24 & 40 \\
\hline Family occupation(main) & 24 & 40 \\
\hline Agriculture & 24 & 40 \\
\hline Business & 12 & 20 \\
\hline Service & 33 & 55 \\
\hline Type of family & 27 & 45 \\
\hline Nuclear & \multicolumn{2}{|l|}{} \\
\hline Joint & 13 & 21.66 \\
\hline Monthly family income (Rs.) & 16 & 26.67 \\
\hline Less than 30,000 & 31 & 51.67 \\
\hline 30,000 to 60,000 & \multicolumn{2}{|l|}{} \\
\hline Above 60,000 & \multicolumn{2}{|c|}{} \\
\hline
\end{tabular}

Data given in the table 1 indicate that all the respondents belonged to Hindu religion and majority of the respondents (63.33\%) belonged to the age group as $40-50$ years followed by 26.66 per cent respondents belonged to $30-40$ years age group. The data pertaining to education revealed that $40 \%$ of respondents were graduates followed by 30 per cent respondents who were qualified up to Secondary. Majority of the respondents were non-working (65\%), had nuclear families (55\%) and family income (51.67\%) above Rs 60,000 per month. Regarding family occupation an equal number of respondents (40\%) belonged to agriculture and business class each.

Table 2:-Frequency of visiting the holy places

\begin{tabular}{|l|c|c|}
\hline Category & Frequency & Percentage \\
\hline Once in a week & 4 & 6.67 \\
\hline Every month & 11 & 18.33 \\
\hline Once in two months & 8 & 13.33 \\
\hline Every six month & 7 & 11.67 \\
\hline Once in a year & 30 & 50.00 \\
\hline
\end{tabular}

Table 2 depicts the data related to frequency of visiting the holy places, it can be seen that half of the respondents used to visit once in a year especially during Kartik Purnima. It was worth noting that women pilgrims used to come once in a week $(6.67 \%)$, every month $(18.33 \%)$ and once in every two months $(13.33 \%)$ respectively.

Reason of performing holy bath

Figure-1 clearly shows that majority of the pilgrims (49\%) visit the holy places due to religious practices followed by family tradition (33\%).

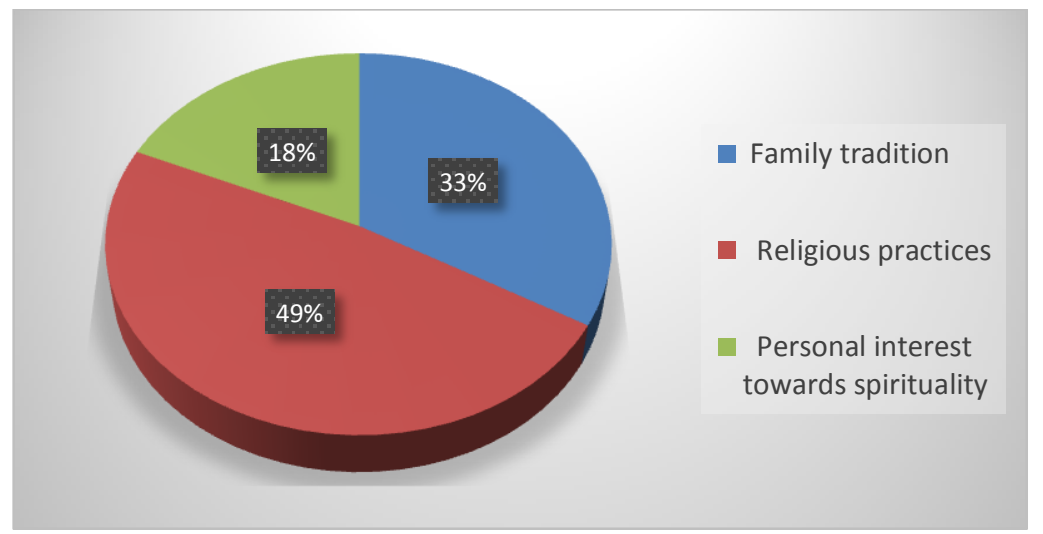

Fig 1:-Reasons of performing holy bath 


\section{Common bath wear used during holy bath}

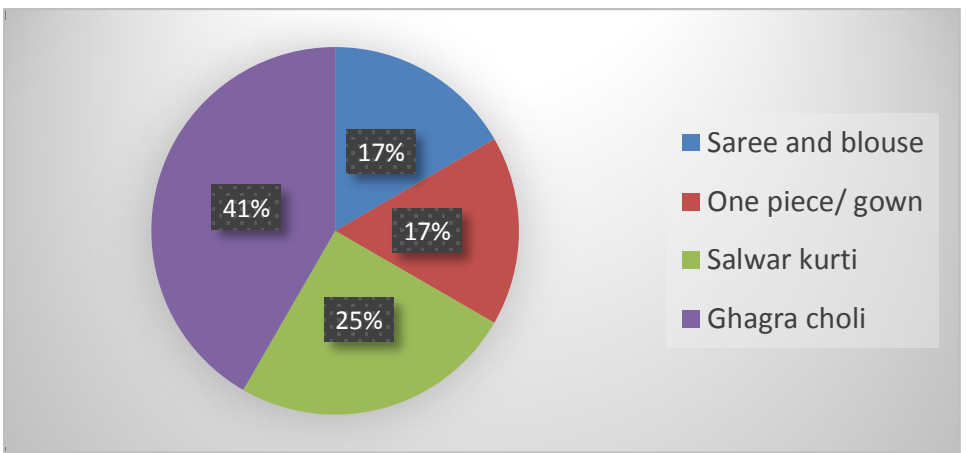

Fig 1:-Common bath wear used during holy bath

Figure-2 clearly shows that majority of the pilgrims did not have any special bathwear they used to wear their casual dresses while performing holy bath. Majority (41\%) used to wear Ghagra choli followed by salwar kurti (25\%). An equal number of pilgrims'(10\%) always wear saree blouse and one piece gown each during holy bath.

\section{Opinion about existing bath wear outfit}

It is evident from Table 3 that maximum respondents $(78.33 \%)$ used to feel very uncomfortable with their present outfit as they found their clothes becoming heavier during bathing and also clings to their body.

Table 3:-Opinion about existing bath wear outfit $\mathrm{n}=60$

\begin{tabular}{|l|l|l|}
\hline Category & \multicolumn{2}{|c|}{ Respondents } \\
\cline { 2 - 3 } & $\mathrm{f}$ & $\%$ \\
\hline Comfortable & 13 & 21.67 \\
\hline Uncomfortable & 47 & 78.33 \\
\hline
\end{tabular}

\section{Problems related to design of the dress}

In response to the question asked regarding structural aspects in dress, making them uncomfortable, data presented in Table 4 depicts that majority of the respondents $(68.33 \%)$ were always having problem with fitting of the dress followed by more than sixty percent respondents who faced problem with disrobing, opening of the dress $(56.66 \%)$, silhouette and neckline shape (deep and wider) by 20 percent each . The problem of off grain fabric was also reported by seventy percent respondents.

Table 4:-Structural design of the dress

\begin{tabular}{|l|l|l|}
\hline \multirow{2}{*}{ Category } & \multicolumn{2}{|c|}{ Respondents } \\
\cline { 2 - 3 } & $\mathrm{f}$ & $\%$ \\
\hline Problem in disrobing & 40 & 66.66 \\
\hline Length of the dress & 11 & 18.33 \\
\hline Fitting of the dress & 41 & 68.33 \\
\hline Shape of the neckline-deep and wide & 12 & 20 \\
\hline Silhouette of the dress & 12 & 20 \\
\hline Opening of the dress & 34 & 56.66 \\
\hline Off grain dress & 42 & 70 \\
\hline
\end{tabular}

*multiple response

Problems related to material used in the dress

Majority of respondents $(85 \%)$ complaint about material used in dress when it comes to modesty in bath wear, they said that semi-transparent/sheer fabric used in dress becomes more figure revealing and clings to the body when its highly absorbent (100\%).

Table 5:-Material used in dress 


\begin{tabular}{|l|l|l|}
\hline & f & $\%$ \\
\hline Sheer fabric & 51 & 85 \\
\hline Soft fabric & 60 & 100 \\
\hline Slippery fabric & 39 & 65 \\
\hline
\end{tabular}

*multiple response

\section{Other problems related to dress}

Researcher also tried to fanout other problems related to dress, in terms of fibre content, colour, texture, weave and drape of the fabric. Table- 6 Depicts that more than fifty percent of the respondents were frequently having problem with fibre content, fabric colour, texture and fabric weave. Problem with fabric weave, texture and drape was always reported by more than 40 percent respondents.

Table 6:-Colour, texture, weave and drape of fabric in dress

\begin{tabular}{|l|l|l|l|l|l|l|}
\hline \multirow{2}{*}{ Category } & \multicolumn{2}{|l|}{ Always } & frequently & \multicolumn{2}{l|}{ Sometimes } \\
\cline { 2 - 8 } & $\mathrm{f}$ & $\%$ & $\mathrm{~F}$ & $\%$ & $\mathrm{f}$ & $\%$ \\
\hline Fibre content & 20 & 33.33 & 31 & 51.66 & 9 & 15 \\
\hline Colour of the fabric & 17 & 28.33 & 34 & 56.66 & 9 & 15 \\
\hline Texture of the fabric & 27 & 45 & 33 & 55 & 0 & 0 \\
\hline Compactness of the weave & 24 & 40 & 36 & 60 & 0 & 0 \\
\hline Drape of the fabric & 30 & 50.00 & 19 & 31.66 & 11 & 18.33 \\
\hline
\end{tabular}

\section{Problems related to constructional features}

An attempt was also made to find out that problems related to constructional features of the bathwear outfits and it was observed that majority of the respondents $(81.66 \%)$ were frequently having problem related to armscye, use of lining and interlining in the dress (80\%), edge finishing(48.33\%) and improper seam lines of neck, sleeve and side seam $\operatorname{area}(41.66 \%)$.

Problems related to dressing and undressing of bath wear outfit

For this investigation, respondents were asked about problems in dressing and undressing of bath wear outfits related to dress opening and fasteners used in dress.

Table 7:-Problems related to dressing and undressing of bath wear outfit

\begin{tabular}{|c|c|c|c|c|c|c|c|}
\hline \multirow[t]{2}{*}{ S.no } & \multirow[t]{2}{*}{ Category } & \multicolumn{2}{|c|}{ Always } & \multicolumn{2}{|c|}{ frequently } & \multicolumn{2}{|c|}{ Sometimes } \\
\hline & & $\mathrm{f}$ & $\%$ & $\mathrm{f}$ & $\%$ & $\mathrm{f}$ & $\%$ \\
\hline I & Garment opening & & & & & & \\
\hline (a) & Narrow slit at neckline & 33 & 55 & 19 & 31.66 & 8 & 13.33 \\
\hline (b) & Without opening & 52 & 86.66 & 8 & 13.33 & 0 & 0 \\
\hline (c) & Side opening & 9 & 15 & 27 & 45 & 24 & 40 \\
\hline (d) & Back opening & 57 & 95 & 3 & 5 & 0 & 0 \\
\hline II & Type of fasteners used & & & & & & \\
\hline (a) & Press buttons & 0 & 0 & 30 & 50 & 30 & 50 \\
\hline (b) & Buttons and buttonhole & 0 & 0 & 25 & 41.66 & 35 & 58.33 \\
\hline (c) & Zippers & 0 & 0 & 24 & 40 & 36 & 60 \\
\hline (d) & Velcro & 0 & 0 & 41 & 68.33 & 19 & 31.66 \\
\hline (e) & Cords & 11 & 18.33 & 32 & 53.33 & 17 & 28.33 \\
\hline (f) & Hooks and eyes & 32 & 53.33 & 28 & 46.66 & 0 & 0 \\
\hline III & $\begin{array}{l}\text { Problems associated with } \\
\text { fasteners }\end{array}$ & & & & & & \\
\hline (a) & Small in size & 30 & 50 & 24 & 40 & 6 & 10 \\
\hline (b) & Too big in size & 0 & 0 & 30 & 50 & 30 & 50 \\
\hline (c) & $\begin{array}{l}\text { Do not open after becoming } \\
\text { wet }\end{array}$ & 41 & 68.33 & 19 & 31.66 & 0 & 0 \\
\hline
\end{tabular}

majority of the respondents (95\%) and (86.66\%) were always having problems with back opening and without opening and narrow slit neck line of the dress $(55 \%)$ while dressing and undressing respectively. Majority (68.33\%) 
were frequently having problems with use of Velcro fasteners in opening the dress in wet state. On the other side (58.33) respondents reported that they sometimes faced problems with buttons and buttonholes also.

Table also depicts that (53.33\%) were frequently having problem with cords used as a fastener in dress and always having problem with hooks and eyes also. Whereas (46.66\%) respondents frequently having problem with hooks and eyes used as a fasteners in the dress while (45\%) and (40\%) respondents responded that they frequently and sometimes having problem with side opening dress, with the same percentile $(40 \%)$ responded that they frequently had problem with zippers and small sized fasteners used in the dress.

\section{Conclusion: -}

The land of Rajasthan is bestowed with a rich cultural heritage which provide a perfect example of dedication and communal harmony among its people. Taking holy bath is one of the important ritual in Hindu culture, but at the same time wearing appropriate bath wear outfit is also a major concern among Indian females at communal places. Finding can be concluded as most of the pilgrims interviewed at the time of data collection were in age group of above 40 years, graduate, nonworking, living in nuclear family, belonged to agriculture /business class and had family income above Rs 50,000 per month. Majotiy of respondents reported lack of comfort in present outfit worn by them during taking holy bath. Problems related to material used in garment such as fibre content, texture, drape and compactness of weave, structural design of the dress and also with the constructional features were highlighted by the respondents.

Hence, it can be said that modest bath wear is the need of the hour for Indian women having religious attitude to perform all rituals with dignity.

\section{References: -}

1. https://www.g-w.com/pdf/sampchap/9781605254630_ch01.pdf)

2. (https://en.wikipedia.org/wiki/Ritual_purification)

3. (https://en.wikipedia.org/wiki/Swimsuit)

4. https://forums.catholic.com/t/swimming-pool-occasion-of-sin/22098

5. https://www.indianholiday.com/tourist-attraction/rajasthan/religious-places

6. (http://www.india.com/travel/pushkar/)

7. Riggs, B. 2009. Modesty, Clothing \& God. Retrieved on June 8, 2017, from http://www.truthaccordingtoscripture.com/documents/articles/modest-clothing.php\#.WTIDz5KGPIU

8. Loch, B.J, 2011. What Is Considered To Be Modest Clothing? Article Dashboard: The web's premiere article directory. Retrieved on 18 June 2017 from http://www.articledashboard.com/Article/What-is-Considered-to-beModest-Clothing/1389735

9. Thomas, M. 2016. Long live the burkini! Indian women have embraced similar swimwear for years. Quartz India. Retrieved on 14 June 2017 from https://qz.com/767390/long-live-the-burkini-indian-women-haveembraced-similar-swimwear-for-years/ 